\title{
LAVADO DE ACTIVOS. CARACTERÍSTICAS, TIPOLOGÍA Y PREVENCIÓN
}

María Fabiola Saquicela Cobos.

Instituto Tecnológico Particular Sudamericano. mfsaquicela@sudamericano.edu.ec

(iD) https://orcid.org/0000-0003-3879-1429

\section{RESUMEN}

En el año 2010 el Ecuador ingresa a la denominada "lista negra" publicada por el organismo internacional GAFI (Grupo de Acción Financiera), debido a los controles deficientes que evidenciaba en temas relacionados a la prevención de lavado de activos. Esto genera un impacto social y cultural a nivel nacional e internacional, pone al país en alerta y permite el inicio de un proceso de actualización de leyes, normas y reglamentos para controlar y prevenir el cometimiento de este delito. El objeto del presente artículo, en este sentido, es dar a conocer algunas de las tipologías usuales del lavado activos, así como describir ciertas medidas necesarias para detectarlas y prevenirlas. Prevenir el delito de lavado de activo es un compromiso de todos, pues cualquier persona está propensa a cometerlo, incluso sin plena conciencia; sin embargo, las sanciones y repercusiones legales no omite a nadie que no logre justificar la tenencia de sus recursos económicos. Los delincuentes que tienen una estructura bien definida para mezclar el dinero, tienen que escoger a personas que desconocen sobre esto, con el fin de tener una "presa fácil". Este delito no es nuevo, ha existido siempre en la sociedad, desde los antepasados, pero es cierto que cada vez se aplican nuevas formas de lavar el dinero y claro que si nuevos actores que colaboran con este hecho, generando así la posibilidad de que el riesgo reputacional se active en una institución, empresa o en el país, lo cual perjudicaría seriamente la imagen de éstas ante la sociedad misma, organismos nacionales e internacionales de trascendencia.

Palabras Clave: tipología, prevención, riesgo, lavado de activos

\author{
Fecha de recepción: \\ 31 de octubre de 2019 \\ Fecha de aceptación: \\ 16 de diciembre de 2019
}

\section{ABSTRACT}

In 2010, Ecuador entered the so-called "black list" published by the international organization GAFI (Financial Action Group), due to the deficient controls that it evidenced in matters related to the prevention of money laundering. This generates a social and cultural impact at the national and international level, puts the country on alert and allows the beginning of a process of updating laws, rules and regulations to control and prevent the commission of this crime. The purpose of this article, in this sense, is to present some of the usual types of money laundering, as well as to describe certain measures necessary to detect and prevent them. Preventing the crime of money laundering is everyone's commitment, since anyone is prone to commit it, even without full awareness; However, the sanctions and legal repercussions do not omit anyone who cannot justify the possession of their economic resources. Criminals who have a well-defined structure to mix money, have to choose people who do not know about it, in order to have an "easy prey". This crime is not new, it has always existed in society, since the ancestors, but it is true that new ways of laundering money are being applied every time and of course new actors who collaborate with this fact, thus generating the possibility that the Reputational risk is activated in an institution, company or in the country, which would seriously damage their image before society itself, national and international organizations of transcendence.

Keywords: typology, prevention, risk, money laundering 


\section{INTRODUCCIÓN}

A lo largo de la historia se pueden encontrar diversas formas de lavado de activos. Se puede recordar, por ejemplo, que en los siglos IX y X, "en un mundo profundamente cristiano en el que cobrar intereses por préstamo u obtener ganancias de transacciones comerciales era considerado un delito severamente castigado" (Villegas, 2014, párr. 2). Posteriormente, en los siglos XVI y XVII, fueron los piratas que atacaban las embarcaciones comerciales que transportaban oro de América a Europa, los que actualizaron las prácticas de lavado de activos.

Ya en el siglo XX, en la década de 1920, fueron los gánsteres que comandaban las mafias norteamericanas, quienes montaron grandes redes de lavanderías para justificar la procedencia ilícita del dinero, presentando los ingresos nacidos de actividades ilícitas como si se trataran de las ganancias del negocio de lavanderías (Seguros Constitución, 2019, párr. 4).

Sin embargo, el boom del lavado de activos (de ahora en adelante: LA) se dio en los años setenta del siglo pasado, y estuvo vinculado al narcotráfico. En esta época, la falta de control en el sistema bancario, permitía que el dinero obtenido de la venta de narcóticos fuera introducido en el sistema financiero y fluctuara dentro de él con normalidad; "sin el lavado de dólares el negocio [del narcotráfico] se arruinaría (Marcos Kaplan citado en Fiscalía General del Estado, 2015, p. 3).

Como es sabido, la problemática que ocasiona el lavado de dinero es un fenómeno de carácter social y económico, y el impacto negativo que genera es alto, ya que provoca descomposición social y afecta considerablemente las operaciones económicas de los países, reduciendo la tasa de crecimiento de la economía.

Con tales antecedentes, el GAFI (Grupo de Acción Financiera Internacional), en la Cumbre del G-7 en París, en 1989, promovió la implementación efectiva de medidas legales, regulatorias y operativas para combatir el LA, el financiamiento del terrorismo y otras amenazas que afecten la integridad del sistema financiero internacional (2010, párr. 1)
Ahora bien, en el caso del Ecuador, el 2010 es un momento de inflexión en relación a las normativas de control del lavado de activo, ya que el Ecuador ingresa a la denominada lista negra publicada por el organismo internacional GAFI, debido a que no poseía una normativa adecuada para prevenir el LA. A partir de entonces se han realizado múltiples esfuerzos para fortalecer la normativa legal del país. Así, en el 2014, el LA es tipificado en el COIP (Código Orgánico Integral Penal) como un delito, y en el 2016 se publica la Ley Orgánica de Prevención, Detección y Erradicación del delito de Lavado de Activos y del Financiamiento de Delitos (vigente hasta la fecha). Como resultado de tales esfuerzos, Diana Salazar, directora de la UAFE (Unidad de Análisis Financiero y Económico) en el año 2018, señaló que, desde enero de 2014 a abril de 2018, se registraron 62 casos de lavado de activos en Ecuador y se recuperó un monto aproximado de 2311746 de dólares, generado por ese delito (Plan V, 2018, párr. 1).

Así pues, el presente artículo se concentra en describir tipologías, alertas y medidas que se pueden adoptar para la prevención de lavado de activos; para ello, se pasa revista a las metodologías adoptadas por los organismos de control, instituciones y leyes creadas y actualizadas en el Ecuador.

\section{Marco normativo en el Ecuador}

En este punto resulta indispensable conocer algunos datos importantes del marco normativo vigente en el Ecuador. Este apartado, así, trae a colación algunos de ellos, indispensables para comprender el fenómeno de lavado de activos a nivel nacional.

Antes que nada, sin embargo, hay que recordar que los organismos de control que contribuyen a la prevención de lavado de activos (de ahora en adelante: PLA) se crearon y fortalecieron en el año 2008, con la aprobación de la nueva Constitución de la República del Ecuador. Desde entonces, se han generado algunos avances al respecto, tal y como puede verse en la Figura 1, en la que se presenta la evolución de la normativa ecuatoriana de PLA. 
Figura 1 » Evolución de la Normativa Ecuatoriana de Prevención de Lavado de Activos.

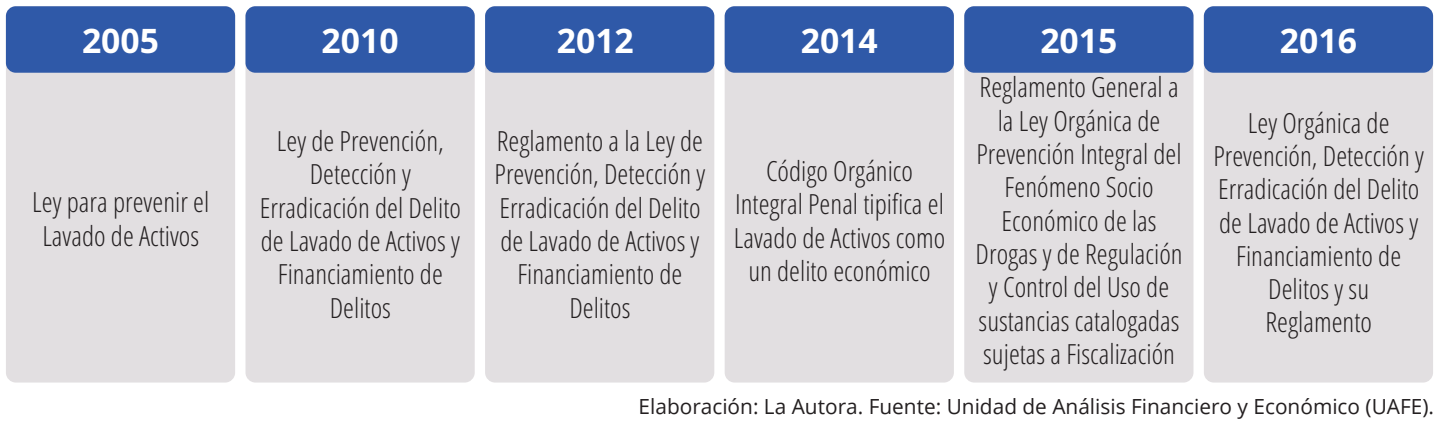

Ahora bien, el organismo encargado directamente de la PLA es la UAFE, institución que se encuentra adscrita al Ministerio de Economía y Finanzas, en virtud de la Ley Orgánica de Prevención, Detección y Erradicación del Delito de Lavado de Activos y Financiamiento de Delitos, expedida el 26 de julio de 2016; esta ley, en su artículo 4, literales c y d, determina que:

Las transacciones individuales o en conjunto, cuya cuantía sea igual o superior a diez mil dólares, y que se encuentren dirigidas a una misma persona, dentro de un período de treinta días, así como también aquellas operaciones inusuales e injustificadas deben ser registradas y reportadas a la UAFE, de manera mensual (pp. 3-4).

En su artículo 5, la misma ley menciona que, a más de las Instituciones del Sistema Financiero Nacional y de las Compañías de Seguros y Reaseguros, serán considerados como sujetos obligados ${ }^{1}$, los pertenecientes a los siguientes sectores económicos: bolsas y casas de valores; administradoras de fondos y fideicomisos; fundaciones y organismos no gubernamentales; personas naturales y jurídicas que se dediquen de forma habitual a la comercialización de vehículos; a la inversión e intermediación inmobiliaria, a la construcción; empresas dedicadas al servicio de transferencia nacional o internacional de dinero o valores; agencias y operadores turísticos; notarios; entre otros.

Ahora, no hay que olvidar que la PLA no sólo requiere de la generación por parte del Estado de un marco nor-

mativo que permita su control, sino que también necesita de la cooperación responsable, tanto de otras partes del sector público como del privado (UAFE, s.f., párr. 1).

\section{La prevención de lavado de activos: definición, características, actividades}

\section{Definición}

Según el GAFI, el LA es el procesamiento de ingresos delictivos a fin de encubrir su origen ilegal, con el objeto de legitimar las ganancias ilícitas de la delincuencia (cualquier actividad ilegal y no solo del tráfico de droga como se lo consideraba años atrás). La UAFE, por su parte, determina que: "comete LA quien adquiera, posea, tenga o use los referidos bienes, con ánimo de lucro, cuando al momento de recibirlos ha conocido su origen ilícito" (UAFE, s., f., párr. 1).

La Dra. Elsa Moreno (2009), por su parte, menciona algunas características que presenta el LA:

- Es una actividad ejecutada generalmente por delincuentes de "cuello blanco" que manejan sumas de dinero muy altas. El delincuente se encuentra, por ende, en una posición económica y social privilegiada.

- Integra un conjunto de operaciones complejas, con características que se salen de los parámetros habituales, de tal manera que se provocan rastros de transacciones complicadas, que compliquen el origen de los recursos.

Sujetos Obligados: son todos los sectores económicos obligados a informar mensualmente a la UAFE, como lo señala la Ley. Las personas naturales o jurídicas que pertenecen a estos sectores económicos se encuentran en la obligación de establecer controles de prevención de lavado de activos y del financiamiento de delitos en todas las operaciones del negocio, con la finalidad que no sean utilizados para el cometimiento de dichos actos ilícitos (UAFE, s.f., párr. 1 y 3). 
- Se da con el uso de un avanzado desarrollo tecnológico, por lo que traspasa canales financieros a nivel mundial.

\section{Etapas}

De acuerdo a lo que menciona la Corporación Nacional de Finanzas Populares y Solidarias (CONAFIPS, 2018, p. 4), el lavado de dinero tiene tres etapas:

- Colocación: consiste en incorporar el producto ilícito en el torrente financiero o no financiero de la economía local o internacional.

- Estratificación: se define por realizar sucesivas operaciones para ocultar, invertir, transformar o dar en custodia bienes provenientes del delito o mezclarlos con dinero de origen legal, con el fin de difuminar su origen ilícito.

- Integración: se refiere a la inversión de los capitales ilícitos, mediante la adquisición de bienes muebles e inmuebles.

\section{Delitos relacionados al LA}

Entre algunas de las actividades o delitos que, según la (UAFE, s.f., párr. 1) provocan el lavado de activos, podemos enumerar:

- Trata de blancas.

- Usura.

- Extorsión

- Narcotráfico.

- Contrabando.

- Piratería.

- Secuestro.

- Peculado.

- Fraude fiscal.

- Sicariato.

- Prostitución.

- Terrorismo.

- Captaciones no canalizadas por el sistema financiero.

- Pornografía.

\section{Prácticas de lavado de activos: una tipología}

El lavado de activos se presenta a través de diversas prácticas; entre ellas, Camila Arévalo (2019) y la Corporación Nacional de Finanzas Solidarias y Populares (2018), pueden destacar las siguientes:
- Pitufeo: consiste en depositar pequeñas cantidades de efectivo en diferentes cuentas de ahorros o corrientes, para evitar los controles de ley (Hildebrandt, 2018, párr. 1).

- Complicidad: se da cuando los autores del lavado de dinero buscan la complicidad de un empleado dentro de la institución en la que laboran para evitar, con su ayuda, los controles.

- Compañías-fachada: son aquellas empresas constituidas legalmente, pero que no desempeñan estrictamente la función que declaran, sino que se han establecido más bien para permitir legitimar dinero ilegal, evadir impuestos, etc.

- Garantías de préstamos: este tipo de lavado de activos se caracteriza porque quien lo hace solicita créditos que, voluntariamente, no paga, provocando que la entidad financiera ejecute la garantía y tome en propiedad los bienes del deudor de dichos bienes. Lo importante, aquí, es que los bienes incautados son productos de actividades delictivas. De esta manera, el "delincuente" obtiene dinero lícito a través de un préstamo, y permite que sus bienes sean embargados.

- Compra de billetes premiados de lotería: el objetivo es contactar a la persona acreedora del premio con el fin de comprar por sumas más altas el boleto o premio, de esta manera, la persona acreedora recibe más valor del que recibiría normalmente y el "delincuente", limpia su dinero a través del boleto.

- Testaferrato: esta modalidad lo usan, generalmente, las personas que se inician en el negocio del lavado de dinero permitiendo que los delincuentes distribuyan su capital entre varias personas, en muchas ocasiones son amigos y familiares, para no generar sospechas. El delincuente controla que dichas cuentas no superen los límites de dinero permitidos.

- Casinos: el delincuente llega a un casino con el efectivo obtenido ilícitamente; cambia ese dinero por fichas de juego y luego se entregan las fichas, obviamente con un margen de pérdida, y el ca- 
sino entrega un cheque, de esta manera se hizo legal el dinero.

\section{Medidas y controles para la PLA}

La Resolución No. 011-2014-F, expedida por la Junta de Regulación Monetaria y Financiera (2016), expone medidas y controles que generalmente adoptan las instituciones del sector financiero y los demás sectores obligados, entre algunas de ellas están:

- Contar tanto con un Manual de PLA y Financiamiento de Delitos como con un Código de Ética; éste último, de hecho, es muy importante ya que en él se enfatiza la responsabilidad moral y ética que deben tener aquellas personas que implementan mecanismos y controles de prevención, con el único fin de detectar y tomar acciones concretas frente al LA u otras formas de delitos. Es importante recalcar que las sanciones y penas relacionadas al LA están tipificados en el COIP, por lo que se debe actuar con independencia y objetividad, de tal manera que se eviten los conflictos de intereses entre clientes internos y externos de la institución.

- Crear y monitorear los perfiles de riesgo de los socios o clientes a través de una Matriz de Riesgo, misma que deberá generar alertas en caso de determinar variaciones en los perfiles económicos de los sujetos.

- Realizar visitas in situ de inspección a sucursales, agencias, oficinas y dependencias, a fin de verificar el cumplimiento de los controles internos.

- Enviar a la UAFE los reportes sobre las operaciones que hayan sido iguales o superiores al umbral de $\$ 10000$, de manera individual o colectiva en un período de 30 días, y remitir el informe de las operaciones inusuales que se hayan identificado.

- Realizar capacitaciones sobre prevención de lavado de activos y financiamiento de delitos a: miembros de los consejos, gerente, funcionarios, socios o clientes, servicios generales y demás miembros de la institución.

- Controlar el cumplimiento de las políticas:
"Conozca a su Socio", "Conozca su Mercado", "Conozca a su Empleado", "Conozca a su Directivo", "Conozca a su Proveedor".

- Generar el formulario de licitud de fondos en todas las transacciones iguales o superiores a $\$ 5$ 000, sean éstos de manera digital o manual. Las instituciones no mantendrán cuentas anónimas, ni suscribirán pólizas a plazo fijo con nombres falsos o de cualquier otra modalidad que encubra la identidad del socio.

- Evitar que las instituciones establezcan relaciones comerciales con sociedades o empresas comerciales constituidas en "paraísos fiscales" (lugares con baja o nula imposición fiscal).

- Solicitar el "Certificado de Homónimo" o el "Certificado de Exclusión", emitido por la UAFE, en caso de tratarse de una persona homónima o sentenciada, respectivamente.

- Controlar a las PEPs -Personas Expuestas Políticamente-

- Investigar fuentes de información adicionales a la existente sobre los socios y clientes, incluyendo la solicitud de los justificativos respectivos, de ser el caso.

\section{CONCLUSIONES}

- Está claro que el delito analizado en los párrafos precedentes es un fenómeno actual, que debería preocupar a los diferentes gobiernos del mundo. $Y$ es que mientras un país sea considerado propicio para el desarrollo del lavado de activos, seguramente atraerá delincuentes, capitales ilícitos y generará corrupción. Afectará, así, no sólo a su composición social sino también a su estabilidad económica y financiera, afectando directamente al ingreso de capital e inversión extranjera.

- En este sentido, es muy importante crear una cultura de prevención en todos los niveles de la sociedad, con el firme objetivo de crear medidas de prevención y control, y permitiendo a los ciudadanos tener una panorámica de los procesos a través de los cuales se desarrolla el LA. 


\section{BIBLIOGRAFÍA}

Arévalo, C. (2019). ¿Cuáles son los métodos del lavado de activos? Recuperado de https://www.riesgoscero.com/blog/cuales-son-los-metodos-del-lavado-de-activos

Asamblea Nacional. (2016). Ley Orgánica de Prevención, Detección y Erradicación del delito de Lavado de Activos y del Financiamiento de Delitos. Quito: Registro Oficial No. 802

Corporación Nacional de Finanzas Solidadrias y Populares-CONAFIPS. (2018). Normativa vigente en Prevención de Lavado de Activos. Recuperado de http://www.finanzaspopulares.gob.ec/wp-content/uploads/downloads/2018/02/Normativa-enprevencio\%CC\%81n-de-lavado-de-activos.pdf

El GAFI se creó en 1989, en París. (20 de febrero de 2010). El Comercio. Recuperado de; https://www.elcomercio.com/actualidad/gafi-creo-1989-paris.ht

Fiscalía General del Estado. (2015). Las cifras del lavado de activos. Nuevas fuentes del delito. Quito: PH Ediciones/industria gráfica.

Hildebrandt, M. (2018). Pitufeo. El Comercio. Recuperado de https://elcomercio.pe/opinion/habla-culta/ martha-hildebrandt-significado-pitufeo-noticia-570347

Junta de Regulación Monetaria y Financiera (2016). Resolución No. 011-2014-F.

Moreno, E. (2009). El Lavado de Dinero y Activos. Derecho Ecuador. Recuperado de

https://www.derechoecuador.com/el-lavado-de-dinero-y-activos

Plan V. (2018). Las Cifras del Lavado de Activos en el Ecuador. Recuperado de https://www.planv. com.ec/historias/politica/cifras-del-lavado-activos-el-ecuador

Seguros Constitución. (2019). Historia Lavado de Dinero. Recuperado de https://segurosconstitucion.com. ec/historia-lavado-de-dinero/
Unidad de Análisis Financiero y Económico - UAFE. GAFI. Recuperado de https://www.uafe.gob.ec/ cooperacion-internacional-gafi/

Villegas, L. (2014). Contribución a la Detección del Delito de Testaferro en el Ecuador. 